\section{Phosphorescent perylene imides $\dagger$}

\author{
Barbara Ventura, ${ }^{a}$ Heinz Langhals, ${ }^{b}$ Bernd Böck ${ }^{b}$ and Lucia Flamigni* ${ }^{a}$ \\ Received 9th February 2012, Accepted 9th March 2012 \\ DOI: $10.1039 / \mathrm{c} 2 \mathrm{cc} 30948 \mathrm{c}$
}

Asymmetrically substituted perylene imide derivatives PIa and PIx display phosphorescence in glassy matrices at $77 \mathrm{~K}$. The lifetime is $49.0 \mathrm{~ms}$ for PIa and $13.5 \mathrm{~ms}$ for PIx. The triplet energy is $1.79 \mathrm{eV}$ for PIa and $1.68 \mathrm{eV}$ for PIx as confirmed by sensitization experiments of the $C_{60}$ triplet.

Perylene bisimides and closely related dyes are attracting increasing interest for their light absorption, high fluorescence, electron transport properties which make them very valuable in colour chemistry, ${ }^{1}$ as fluorescence tags ${ }^{2}$ and in organic electronics. ${ }^{3}$ Due to their high stability and intense spectroscopic signatures these excellent electron acceptors have often been used as components in arrays for light energy conversion both for practical purposes ${ }^{4}$ and for mechanistic studies. ${ }^{5-7}$

We recently reported on the photophysical and electrochemical properties of a couple of new asymmetrically substituted perylene imide derivatives, PIa and PIx (Fig. 1). ${ }^{8}$ A remarkable feature of these new PIs is an intrinsic high triplet yield, an unprecedented feature for this class of compounds. Triplet reactivity for PIs has been formerly reported only as a consequence of inter-molecular ${ }^{9}$ or intra-molecular sensitization ${ }^{10-12}$ or under conditions of induced enhancement of triplet yield in multi-component arrays. ${ }^{13,14}$ In the present asymmetrically substituted PIs, in spite of a still high fluorescence quantum yield $\left(\phi_{\mathrm{fl}}=0.37\right.$ for PIa and $\phi_{\mathrm{fl}}=0.58$ for PIx), a high triplet yield of the order of $1-\phi_{\mathrm{fl}}$ was observed. For both PIs the triplet-triplet absorption spectrum, with intense bands at around $510-530 \mathrm{~nm}$, was registered and a triplet lifetime in air purged solutions of the order of $10^{2} \mu$ s was measured at room

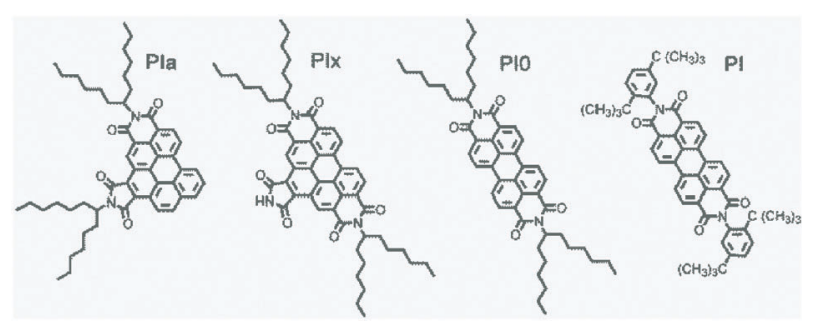

Fig. 1 Structures of the asymmetrically substituted perylenes PIa, PIx and of the parent perylenes PIO and PI.

${ }^{a}$ Istituto ISOF-CNR, Via P. Gobetti 101, 40129 Bologna, Italy.

E-mail: flamigni@isof.cnr.it

${ }^{b}$ Department of Chemistry, LMU University of Munich,

Butenandtstr. 13, D-81377 Munich, Germany

$\dagger$ Electronic supplementary information (ESI) available: Experimental methods and additional photophysical data. See DOI: 10.1039/ c2 2 c30948c

temperature. The reaction rate with oxygen, $k_{\mathrm{ox}}$, was of the order of $2 \times 10^{9} \mathrm{M}^{-1} \mathrm{~s}^{-1}$. We provided evidence, by measuring the singlet oxygen $\left({ }^{1} \Delta_{\mathrm{g}}\right)$ luminescence at $1268 \mathrm{~nm}$, of the sensitization of singlet oxygen by PIa and PIx with yields of the order of $0.4-0.6$.

These values are those of typical singlet oxygen photosensitizers and suggest that these compounds can be used for this purpose. We also looked for phosphorescence in the glassy matrix of toluene (TL) and, on the basis of the known triplet energy level of the parent symmetric compound PI, ca. $1.2 \mathrm{eV},{ }^{9}$ we looked for bands in the NIR range. For PI, former sensitization experiments allow to derive the energy level of the triplet since the intersystem crossing (isc) yield for this compound is almost zero. ${ }^{9}$

In the NIR range, very weak bands emerging from the fluorescence background of the PIa and PIx samples, absent in the parent compound PIO, could be identified in TL glassy matrixes. These bands were around 900 and $990 \mathrm{~nm}$ for PIa and in the region 920-990 $\mathrm{nm}$ for PIx. Similar band values were measured for PIa in a 3-methylpentane glass, but the maxima of PIx in a dichloromethane-methanol glass were not confirmed (Fig. S1, ESI $\dagger$ ). In fact a single broad band at around $950 \mathrm{~nm}$ could be detected and this casts doubts on the correctness of the previous assignment. ${ }^{8}$ In the present study we intend to address in more detail the phosphorescence issue, to measure a reliable phosphorescence spectrum and derive the triplet excited state energy in order to fully characterize this state for the two compounds.

Absorption at room temperature and luminescence spectra at room temperature and $77 \mathrm{~K}$ in TL detected in the UV-Vis region are reported in Fig. 2. The high fluorescence background in the $600-850 \mathrm{~nm}$ region does not allow us to detect the comparatively weaker phosphorescence bands.

In order to enhance phosphorescence and be able to locate the phosphorescence emission region, we take advantage of the heavy atom effect on the isc of the compounds. This is expected to greatly enhance isc by increasing spin-orbit coupling and to quench the fluorescence in favour of phosphorescence. The corrected luminescence spectra of the new PIs in glassy solutions $(77 \mathrm{~K}$ ) containing $50 \%$ of ethyl iodide (EtI) are measured both with a NIR sensitive spectrofluorimeter and a UV-Vis spectrofluorimeter. They are reported in Fig. 3. The spectra from the two different apparatuses are in excellent agreement and show intense bands respectively at 686, 764 and $862 \mathrm{~nm}$ for PIa and 737, 830 and $948 \mathrm{~nm}$ for PIx. One can notice that the bands formerly detected above $900 \mathrm{~nm}^{8}$ (Fig. S1, ESI $\dagger$ ) may represent only the weakest low energy tail of the phosphorescence. Excitation spectra measured on the maxima of the luminescence in the glassy matrix 


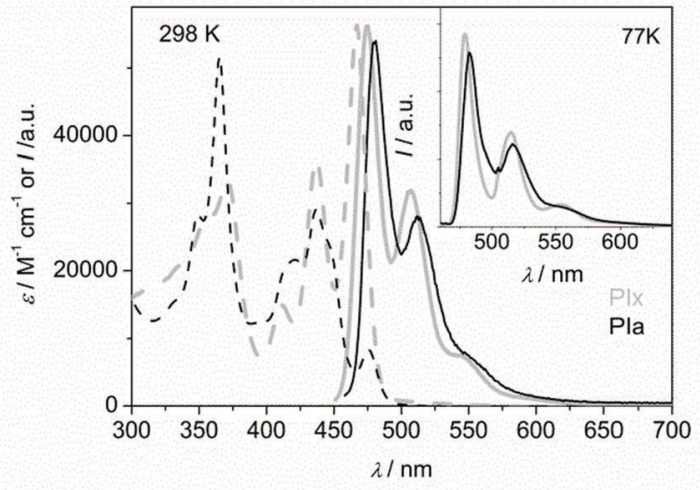

Fig. 2 Absorption spectra of PIa and PIx (dashed line) and arbitrarily scaled luminescence spectra in the UV-Vis region at $298 \mathrm{~K}$ (continuous line) in TL. The luminescence spectra in the UV-Vis region in TL glass at $77 \mathrm{~K}$ are shown in the inset.

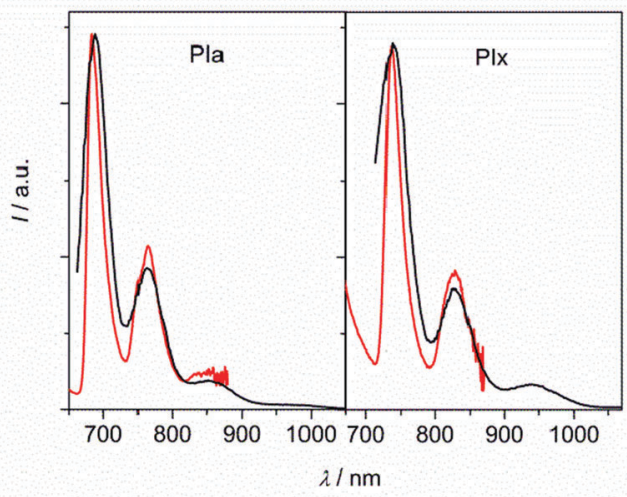

Fig. 3 Corrected luminescence spectra in a DCM-MeOH-EtI $(1: 1: 2)$ glass at $77 \mathrm{~K}$ measured with a NIR (black line) and a UV-Vis spectrofluorimeter (red line).

containing 50\% EtI, Fig. S2 (ESI $\dagger$ ), are in good agreement with the absorption spectra of the solutions, see Fig. 2. This confirms that the observed emissions are indeed produced upon excitation of the PIs and not as a consequence of artefacts or contaminants.

A more direct measure of the phosphorescence in normal, nonheavy atom containing solvents requires a gated detection. This prevents the very strong prompt fluorescence signal from reaching the detector. Gated detection is available only on the UV-Vis spectrofluorimeter, with sensitivity dropping above $850 \mathrm{~nm}$. The uncorrected delayed luminescence of PIa and PIx in a 1:1 mixture of dichloromethane-ethanol (DCM-EtOH) at $77 \mathrm{~K}$ is reported in Fig. 4. The spectra show bands at wavelengths of 692 and $762 \mathrm{~nm}$ for PIa and 734 and $820 \mathrm{~nm}$ for PIx, in very good agreement with those obtained in the heavy-atom containing solvent. This confirms a genuine phosphorescent nature for the emission. The lifetime measured at $77 \mathrm{~K}$ in a DCM-MeOH $(1: 1)$ matrix is $13.5 \mathrm{~ms}$ for PIx and $49.0 \mathrm{~ms}$ for PIa, respectively (Fig. S3, ESI $\dagger$ ).

The triplet excited state energy, derived from the phosphorescence band, is $1.79 \mathrm{eV}$ for PIa and $1.68 \mathrm{eV}$ for PIx. This value is $0.5-0.6 \mathrm{eV}$ higher than that reported for PI. ${ }^{9}$ The large difference in the triplet excited state is somehow surprising, since

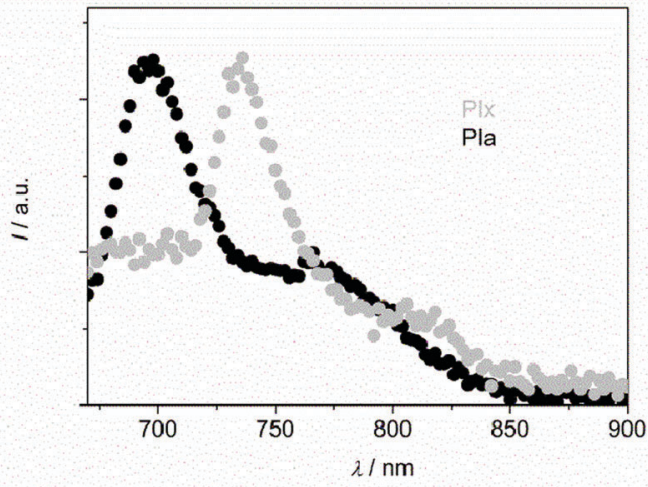

Fig. 4 Delayed luminescence spectra of PIa and PIx in a DCM-MeOH $(1: 1)$ glassy solution at $77 \mathrm{~K}$. Both have been registered with a delay of $50 \mu \mathrm{s}$ after the pulse of the lamp and with a gate open for $20 \mathrm{~ms}$.

the singlet excited state energy level in PIa and PIx is only $0.3 \mathrm{eV}$ higher than that of model PI0. The $77 \mathrm{~K}$ fluorescence maximum is in fact at $483 \mathrm{~nm}(2.56 \mathrm{eV})$ for PIa and at $479 \mathrm{~nm}(2.58 \mathrm{eV})$ for PIx compared to a $543 \mathrm{~nm}(2.28 \mathrm{eV})$ fluorescence maximum for PIO.

To confirm the unexpectedly high energy level of the triplet excited state of these PIs, we designed a sensitization experiment with a partner of known, lower triplet energy. In these experiments, the PIs triplet can act as energy donor and sensitize the triplet excited state of the acceptor. PIs display intense $\mathrm{T}-\mathrm{T}$ absorption bands in TL solutions at room temperature, with maxima at $510 \mathrm{~nm}$ ( $\varepsilon$ ca. $7000 \mathrm{M}^{-1} \mathrm{~cm}^{-1}$ ) for PIa and at $530 \mathrm{~nm}$ ( $\varepsilon$ ca. $14000 \mathrm{M}^{-1} \mathrm{~cm}^{-1}$ ) for PIx. ${ }^{8}$ Fullerene $\left(\mathrm{C}_{60}\right)$ is identified as a convenient energy acceptor since it is a good electron acceptor ${ }^{15}$ and therefore thermodynamically unable to undergo electron transfer reactions with the strongly electron deficient PIs. $\ddagger$ The triplet energy level of the fullerene is $1.57 \mathrm{eV}$, slightly lower than that found for the two PIs, and its triplet is well characterized by an absorption band at around $750 \mathrm{~nm} .{ }^{16}$ Furthermore, selective excitation of PIs can be achieved at around $470 \mathrm{~nm}$ (Fig. S4, ESI $\dagger$ ).

The results of flash photolysis experiments upon selective excitation of PIx at $467 \mathrm{~nm}$ in a solution containing $\mathrm{C}_{60}\left(5 \times 10^{-5} \mathrm{M}\right)$ are shown in Fig. 5. Fig. S5 (ESI $\dagger$ ) shows the results of a similar experiment where PIa, excited at $476 \mathrm{~nm}$, is the sensitizer. In both cases the bands of PIs triplets decay at a faster rate than the one measured in oxygen free $\mathrm{TL}$ solutions in the absence of $\mathrm{C}_{60}$ ( $\tau=140 \mu$ s for PIx and $\tau=130 \mu$ s for PIa) whereas the band of $\mathrm{C}_{60}$ at $740 \mathrm{~nm}$ grows as shown in Fig. 5 and Fig. S5 (ESI $\dagger$ ). The lifetime of the decay of the ${ }^{3}$ PIs band and of the concomitant rise of the sensitized ${ }^{3} \mathrm{C}_{60}$ depends on the concentration of the $\mathrm{C}_{60}$ quencher (Fig. 6). The bimolecular energy transfer rate constant is $k_{\text {en }}=4.0 \times 10^{9} \mathrm{M}^{-1} \mathrm{~s}^{-1}$ for PIx and $k_{\mathrm{en}}=5.4 \times 10^{9} \mathrm{M}^{-1} \mathrm{~s}^{-1}$ for PIa. The relative magnitude of the rates for the two PIs reflects the higher driving force of the energy transfer reaction when PIa is used as sensitizer $\left(\Delta G^{0}=-0.22 \mathrm{eV}\right)$ than when PIx is used as sensitizer $\left(\Delta G^{0}=-0.11 \mathrm{eV}\right)$. On the other hand, the absolute value of the two rates, lower than the diffusional one $\left(1 \times 10^{10} \mathrm{~s}^{-1}\right)$, is typical of exothermic triplet energy transfer reactions. The data from sensitization experiments, showing an efficient sensitization of the triplet of $\mathrm{C}_{60}$, are consistent with the triplet energies for the two PIs derived from phosphorescence experiments. 


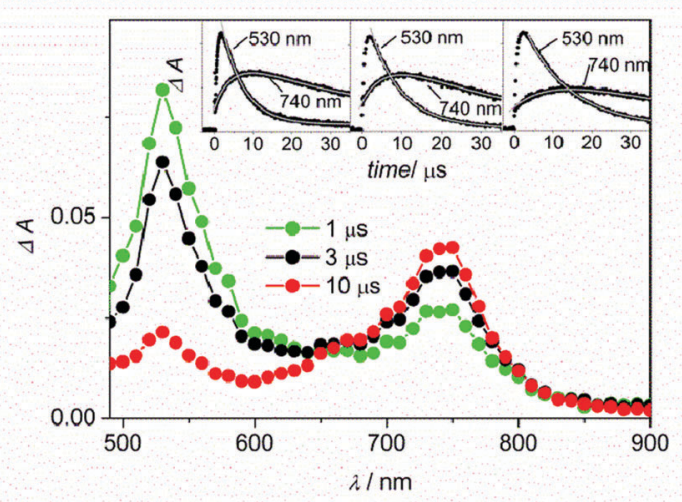

Fig. 5 Transient absorption spectra of PIx $\left(2.4 \times 10^{-5} \mathrm{M}\right)$ in TL in the presence of $\mathrm{C}_{60}\left(5 \times 10^{-5} \mathrm{M}\right)$ at room temperature. Excitation at $467 \mathrm{~nm}$, $0.6 \mathrm{~mJ}$ pulse $^{-1}$. In the inset the time evolutions of the absorbance on the band maxima at $\mathrm{C}_{60}$ concentrations of $5 \times 10^{-5} \mathrm{M}$ (left), $3.7 \times 10^{-5} \mathrm{M}$ (centre) and $2.8 \times 10^{-5} \mathrm{M}$ (right) are shown.

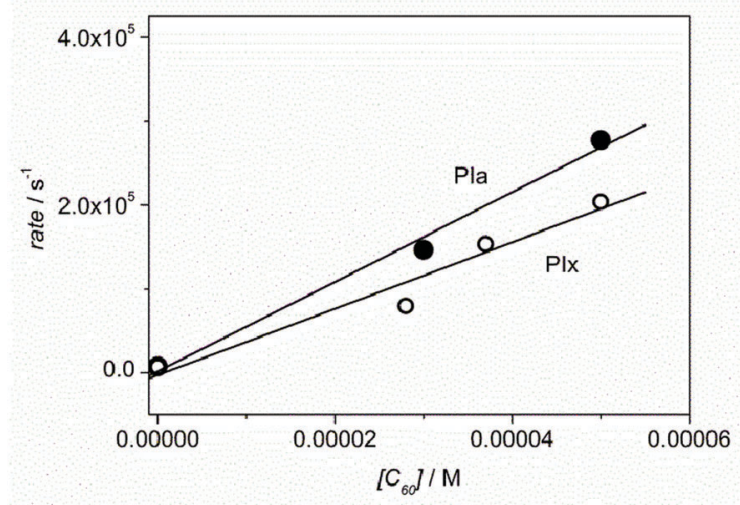

Fig. 6 Pseudo-first order rate constant for the energy transfer process in TL solutions from ${ }^{3} \mathrm{PIx}$ and ${ }^{3} \mathrm{PIa}$ in the presence of different $\mathrm{C}_{60}$ concentrations.

We have here reported for the first time phosphorescent perylene imides. Phosphorescence induced by an external heavy atom effect in EtI glasses has helped to locate the phosphorescence bands which have been confirmed by delayed luminescence experiments in non-heavy atom containing glassy solvents. The triplet energy levels, $1.79 \mathrm{eV}$ for PIa and $1.68 \mathrm{eV}$ for PIx, remarkably high for perylene imides, have been confirmed by sensitization experiments of ${ }^{3} \mathrm{C}_{60}$. Altogether, the designed experiments confirm the assignment of the bands as unquestionable genuine phosphorescence and open the way to new applications for these dyes.

\section{Notes and references}

$\ddagger \mathrm{C}_{60}$ reduces at $-0.98 \mathrm{~V}$ and oxidizes at $+1.26 \mathrm{~V}$ vs. $\mathrm{Fc} / \mathrm{Fc}^{+}$in acetonitrile-toluene $(1: 5)^{15}$ which can be converted as $c a$. $-0.55 \mathrm{~V}$ and $c a$. $+1.7 \mathrm{~V} v s$. SCE. The first reduction of PIx is at $-0.58 \mathrm{~V}$ and that of PIa at $-0.96 \mathrm{~V}$, whereas the oxidation wave is above $1.9 \mathrm{~V}$ for PIx and at $1.75 \mathrm{~V}$ for PIa, all vs. SCE. ${ }^{8}$ The energy stored in ${ }^{3} \mathrm{PIs}$ $(\leq 1.79 \mathrm{eV})$ is not sufficient to provide either HOMO-HOMO or LUMO-LUMO electron transfer.

1 (a) H. Zollinger, Color Chemistry, Wiley-VCH Weinheim, 3rd edn, 2003; (b) H. Langhals, Helv. Chim. Acta, 2005, 88, 1309-1343; (c) F. Würthner, Chem. Commun., 2004, 1564-1579.

2 T. Weil, T. Vosch, J. Hofkens, K. Peneva and K. Müllen, Angew. Chem., Int. Ed., 2010, 49, 9068-9093.

3 X. Zhan, A. Facchetti, S. Barlow, T. J. Marks, M. A. Ratner, M. R. Wasielewski and S. R. Marder, Adv. Mater., 2011, 23, 268-284.

4 C. Li and H. Wonneberger, Adv. Mater., 2012, 24, 613-636.

5 (a) M. P. O' Neil, M. P. Niemczyk, W. A. Svec, D. Gosztola, G. L. Gaines III and M. R. Wasielewski, Science, 1992, 257, 63-65; (b) M. J. Ahrens, L. E. Sinks, B. Rybtchinski, W. Liu, B. A. Jones, J. M. Giaimo, A. V. Gusev, A. J. Goshe, D. M. Tiede and M. R. Wasielewski, J. Am. Chem. Soc., 2004, 126, 8284-8294; (c) M. R. Wasielewski, J. Org. Chem., 2006, 71, 5051-5066.

6 (a) A. Marcos Ramos, S. C. J. Meskers, E. H. A. Beckers, R. B. Prince, L. Brunsveld and R. A. J. Janssen, J. Am. Chem. Soc., 2004, 126, 9630-9644; (b) E. H. A. Beckers, S. C. J. Meskers, A. P. H. J. Schenning, Z. Chen, F. Würthner, P. Marsal, D. Beljonne, J. Cornil and R. J. Janssen, J. Am. Chem. Soc., 2006, 128, 649-657; (c) C. Flors, I. Oesterling, T. Schnitzler, E. Fron, G. Schweitzer, M. Sliwa, A. Herrmann, M. van der Auweraer, F. C. de Schryver, K. Mullen and J. Hofkens, J. Phys. Chem. C, 2007, 111, 4861-4870; (d) M. Lor, J. Thielemans, L. Viaene, M. Cotlet, J. Hofkens, T. Weil, C. Hampel, K. Müllen, J. W. Verhoeven, M. van der Auweraer and F. C. de Schryver, J. Am. Chem. Soc., 2002, 124, 9981-9985; (e) F. J. Céspedes-Guirao, K. Ohkubo, S. Fukuzumi, Á. SastreSantos and F. Fernández-Lázaro, J. Org. Chem., 2009, 74, 5871-5880.

7 (a) L. Flamigni, B. Ventura, M. Tasior, T. Becherer, H. Langhals and D. T. Gryko, Chem.-Eur. J., 2008, 14, 169-183; (b) L. Flamigni, B. Ventura, C.-C. You, C. Hippius and F. Würthner, J. Phys. Chem. C, 2007, 111, 622-630; (c) A. I. Oliva, B. Ventura, F. Würthner, A. Camara-Campos, C. A. Hunter, P. Ballester and L. Flamigni, Dalton Trans., 2009, 4023-4037.

8 L. Flamigni, A. Zanelli, H. Langhals and B. Böck, J. Phys. Chem. $A, 2012,116,1503-1509$.

9 (a) W. E. Ford and P. Kamat, J. Phys. Chem., 1987, 91, 6373-6380; (b) T. Kirchner and H.-G. Loehmannsroeben, Phys. Chem. Chem. Phys., 1999, 1, 3987-3992.

10 A. Prodi, C. Chiorboli, F. Scandola, E. Iengo, E. Alessio, R. Dobrawa and F. Würthner, J. Am. Chem. Soc., 2005, 127, 1454-1462.

11 (a) A. A. Rachford, S. Goeb and F. N. Castellano, J. Am. Chem. Soc., 2008, 130, 2766-2767; (b) E. O. Danilov, A. A. Rachford, S. Goeb and F. N. Castellano, J. Phys. Chem. A, 2009, 113, $5763-5768$.

12 (a) J. Baffreau, S. Leroy-Lhez, P. Hudhomme, M. M. Groeneveld, I. H. M. van Stokkum and R. M Williams, J. Phys. Chem. A, 2006, 110, 13123-13125; (b) J. Baffreau, S. Leroy-Lhez, N. V. Anh, R. M. Williams and P. Hudhomme, Chem.-Eur. J., 2008, 14, 4979-4992.

13 D. Veldman, S. M. A. Chopin, S. C. J. Meskers and R. A. J. Janssen, J. Phys. Chem. A, 2008, 112, 8617-8632.

14 D. Veldman, S. M. A. Chopin, S. C. J. Meskers, M. M. Groeneveld, R. M. Williams and R. A. J. Janssen, J. Phys. Chem. A, 2008, 112, 5846-5857.

15 L. Echegoyen and L. E. Echegoyen, Acc. Chem. Res., 1998, 31, 593-601.

16 (a) D. M. Guldi and M. Prato, Acc. Chem. Res., 2000, 33, 695-703; (b) Y. Zeng, L. Biczok and H. Linschitz, J. Phys. Chem., 1992, 96, 5237-5239. 